\title{
Infrastructure projects financing. An alternative to debt financing
}

\author{
Ashfaq Ahmad (M. Phil Scholar), Muhammad Zaheer (M. Phil Scholar), \\ Salman Masood (Ph.D Scholar), Saqib Usman (M. Phil Scholar), \\ Superior University Lahore.
}

\begin{abstract}
There is high unemployment and high inflation in developing countries like Pakistan. These countries can attract foreign direct investment by improving their infrastructure and education facilities. But they do not have huge amounts to finance these projects. So they have to turn to IMF, World Bank and other international financial institutions for expensive loans with strict terms and conditions. This paper presents an alternative to these costly loans with no strict condition. A model has been adopted to express the working of this financing mode. Qualitative approach has been used to collect data from different articles. By following the examples of Malaysia, UAE, Qatar and Indonesia, Pakistan and many other developing countries can easily attract huge funding for infrastructure projects as there is a high demand for Sovereign Sukuks in the international market. The basic requirement of Sovereign Ijarah Sukuks is underlying assets.
\end{abstract}

Key Words: Sovereign Sukuks, Rate of Return, Economic Development

\section{Introduction}

There is very low foreign direct investment in developing countries due to many known reasons. The basic reason is that these countries lack physical, telecom, technological infrastructure and the quality of human resources is also very low in these countries. To develop infrastructure and educational institutions in these developing countries, huge amounts are required which these countries are unable to appropriate in their budgets. These countries go for foreign loans from international institutions which are very costly with squeezed conditions. In this paper we try to provide an alternative to these foreign loans. This alternative is not a new thing to many or it is also not a theoretical thing to consider in the books only. This is very much practical and many countries have taken benefit from this huge resource of funds.

This is Islamic Bond, an alternative to conventional bond. The main difference between conventional bond and an Islamic bond is that, conventional bond is not backed by any asset but Islamic bond is backed by some tangible asset. There are different kinds of Islamic bonds available but in this paper we are focusing only on Sovereign Ijarah Sukuk (an asset backed Islamic Bond). With the help of these Sukuk, recently many countries have raised huge amounts at least in US dollars to finance their public projects. This has been true in the case of Malaysia, UAE, Indonesia, Bahrain and Saudi Arabia.

As a benchmark, Malaysia is the best example of sovereign Sukuks issues. According to Nurul Aini \& Rafisah Mat Radzi (2011), Malaysia acheived a milestone in 2002 when it issued its first sovereign Sukuks of US\$ 600 million. This issuance was listed on the Luxembourg Stock Exchange, Labuan International Financial Stock Exchange and Bahrain Stock Exchange. Malaysia and GCC countries have big shares in international sovereign Sukuks and Germany, Indonesia, Pakistan and United States have also nominal shares in global sovereign Sukuks issues, A. Roger Wedderburn-Day (2010). Islamic Finance News. (2012) reports that the year 2012, has seen positive actions in issuing Sukuks from Middle East countries due to high public expenditure on the back of high oil prices and a thinking of diversifying their surplus funds.

If Sovereign Sukuks are issued in the local currency, it would be highly beneficial for the country to control inflation in the short as well as in the long run. If these issues are made through the State Banks of developing countries, then this would surely help to confine inflation at one hand and at the other hand huge funds would be available for the country to raise infrastructure of the country and provide different opportunities for the general public in the form employment and high living standard. All this could be done without affecting the balance sheet of the country. The only thing that should be taken care of is to explore the markets world over to raise huge finances. Alongside, political will of the Government is direly required with consistency in the public policy of the Government despite the changes of the parties in power.

Sovereign Sukuks phenomenon is not restricted to developing nations or only Muslim nations. Many developed countries are also considering issuing Sovereign Sukuks to raise funds to finance the public sector projects. These countries include Germany, United Kingdom, France, Japan, China, USA and some other countries also considering this option. Some of these countries have already issued Sovereign Sukuks like Germany. 
Another aspect that needs to be taken care of is that, is there huge money available in the international markets? The answer to this important question is Yes. Why? Because almost all the Sovereign Sukuks whether issued by Muslim or Non-Muslim countries mostly have been oversubscribed.

Global financial crisis of 2008 has changed the mind of global investors and they are finding alternative ways to invest. Sovereign Sukuks are the best alternative for them in the medium term at least. And rate of return and their investment would also be highly secured as these Sukuks are provided with sovereign guarantee and asset backing. Alongside, A. Roger Wedderburn-Day (2010), states that a benchmark and legal framework for issuing Sukuks in the relevant country is very important. Islamic Finance News (2012), explains that investors from Europe and the US are being attracted towards Sovereign Islamic Sukuks as a safe place from the turmoil of 2008 crisis.

In the long run some Sukuks holders may be given the chance to convert their Sukuks to shares in the case of corporate Sukuks issues. According to Mohamad Zaid Mohamad Zin, (2011), "After introducing the first sovereign global Sukuks in the world in 2002, Malaysia has continued its success by introducing innovative Sukuks structures such as convertible musyarakah Sukuks by Khazanah Nasional Berhad, the Malaysian government investment holding company. This is a historic issue of the first of its kind in the world, which combines the features of the full convertibility, and it is usually only used for conventional equity-linked transactions, Central Bank of Malaysia."

The most important aspect of the Sukuks issuance is the macro-economic position of the country. But given the success of previous Sukuks issues by Pakistan, Malaysia and GCC countries, it is expected that it would not be big point to consider. And if these huge amounted Sukuks are issued, it would be a great success if the funds are managed and used efficiently and effectively. Corruption and bureaucratic procedures should not hamper this huge investment. But literature suggests that stability of macro-economic indicators is not of ultimate importance as Jordan, Palestine, Nigeria, Senegal, Kenya, Egypt and Kazakhastan have announced their plans to issue sovereign Sukuks, Islamic Finance News (2011).

\section{Literature Review}

Sovereign Sukuks have played very important role in the development of countries as it is proved in the short history of sovereign Sukuks. Developing as well as developed nations can benefit to a large extent by sovereign Sukuks issues. Governments can fulfill their fiscal deficits by issuing sovereign Sukuks. If huge money is required for building big projects like roads, dams, housing colonies, airports then issuing sovereign Sukuks is the best available option in the medium run as well as in the long run. Islamic Finance News (2012), reports that Indonesia is expected to issue sovereign Sukuks of US\$ 24 billion in 2012 and is expected to spend US\$ 445 billion until 2025 for infrastructure projects.

According to International Islamic Financial Market (2011) Sukuks Report, after 2008 global financial crisis the demand for Sukuks was at the lower side but Sukuks issued by Bahrain, Qatar, Indonesia, Malaysia and Pakistan have provided support to Sukuks market and kept its potential intact. Many countries are using Sovereign Sukuks issues to finance their fiscal deficits and even the European countries are thinking and working on issuing sovereign Sukuks to finance their fiscal deficits in these difficult years. But no concrete attempt has been made yet.

Accordingly, there are legal aspects of issuance of sovereign Sukuks issues. Sukuks are issued following the Islamic Law, but all the countries generally have separate civil law, so conformity between these laws is very important. According to Qais H Hamza (2006), Qatar is the best example of this landmark issue of reconciliation between Islamic and Civil Law. "Shariah jurists in the Islamic jurisdictions should not sacrifice Islamic principles for the sake of expediency in approving what is put forward as "innovative" Islamic products", Qais H Hamza (2006).

Rate of return on Sukuks is based on LIBOR plus or economic growth of the country issuing Sukuks. But mostly LIBOR plus is used for issuing Sukuks. Islamic Finance News (2011) has reported that Luxmebourg for France has deferred Sukuks because right underlying assets were not available. So recognition of best available assets is very important for issuing sovereign Sukuks. Dubai World and Malaysia have used suitable assets for Sukuks issuing.

Sovereign Sukuks are being issued by ASEAN countries and also by GCC countries to use surplus funds for the economic development of their respective countries. They are consistently and continuously using these Sukuks to finance their public sector projects. In this way employment is generated and living standard of the people goes up. And this is very simple that when a big project is started the whole economy moves on and even the economies of the other countries also move. According to Kuwait Finance House Report (2011), sovereign Sukuks issuance could be a benchmark for corporate Sukuks issuances to gauge the investors' appetite for the Sukuks market.

Islamic Finance News (2012) reports that "The primary Sukuks market has been driven by the increasing number of funds raised by sovereigns and central banks to soak up excess liquidity and provide short-term 
investment," a report by KFH Research said. To control the inflation in a country it is very beneficial to issue sovereign Sukuks. Surplus money in the market can be accumulated for any big project and it could be two way benefits for the country. But to control the inflation by issuing Sukuks, it is very important to note that these Sukuks must be issued in local currency.

Another aspect of sovereign Sukuks issuance in the international markets is that difference between cultures and social living can be understood and more harmony can be created among nations in the world. Diversification of funds would help in understanding each other's areas and these help in understanding positive cultural and political aspects of East and West.

Germany, Malaysia, Qatar, Bahrain, Saudi Arabia have issued Sukuks to finance their diversified needs especially infrastructure projects. Practically, only Germany has entered the field of Sukuks in Europe by issuing US \$ 141 million Sukuks in 2004, Islamic Finance News. (2011). As France is a secular state, so it is planning to promote Islamic Banking without naming it as Islamic Banking in order to avoid religious sensitivities, Islamic Finance News (2011). The UK has been considering issuing sovereign Sukuks but delayed it until now because of political climate, a lack of demand, a weak uptake of two treasury bonds, slowing down economic growth and budget deficit, Islamic Finance News (2011). According to Prof. Mahmood Faruqui, GCC countries, Accounting and Auditing Organization for Islamic Financial Institutions, Islamic Financial Services Board, Bahrain Monetary Agency, Bank Negara Malaysia, Islamic Development Bank, Dubai Financial Services Authority and many other scholars and lawyers have helped in issuing Sukuks. Hence, Western investors should take advantage of the experience of these countries.

Developed countries like UK and France are hesitating to issue sovereign Sukuks because of initial high cost of issuing and lack of basic infrastructure to issue sovereign Sukuks. Islamic Finance News (2011) reports that the countries who are unable to issue sovereign Sukuks until now, they have basic reasons. First, cost of Sukuks origination is more than issuing conventional bonds. Two, there is no basic Shariah compliant financial tax and legal infrastructure. Islamic Finance News (2011) also explains a statement by a banker that in conventional bonds one seeks for LIBOR minus but in Sukuks one should be ready for LIBOR plus. And if we add currency risk, then this cost would go even high. But China has overcome this issue by issuing certificates in two currencies. For example, we want to raise US\$1 billion from the market. We would divide 400 million in US dollars and 600 million in Euro. This is very simple and a huge loss of foreign exchange fluctuations may be avoided (Ali Arsalan Tariq, 2004).

Any country which issues sovereign Sukuks, it would have available widened amounts from all over the world. Investors in the form of governments and also corporate investors may have the opportunity to invest in the sovereign Sukuks issued by the respective country. Islamic Finance News (2011) reports that Marc Theisen of Theisen Law in Luxembourg, has said that ethical avenue of funds availability is through sovereign Sukuks, for both Muslims and Non-Muslims interested in ethical investment.

Islamic Finance News (2011) reports that institutional and high net worth individuals are seeking to invest in sovereign Sukuks because of volatile economic conditions and they see sovereign Sukuks as secured investment due to its asset-backed nature. Sovereign Sukuks are so much strong because they have the sovereign guarantee behind them which is not the case with corporate Sukuks. Sovereign Sukuks, generally speaking is a world of opportunity. Investors get their rental payments in time at LIBOR plus and at the end of the agreement they receive their principal amount. According to Qais H Hamza (2006), Sukuks issuance also helps in convergence of standards and opportunities. This is possible in the way that investors from one part of the world say Europe may invest in GCC region. This would help understand laws and other tax and financial regulations of each other's country and then making maximum efforts to bring them in maximum possible conformity and harmony.

According to International Islamic Financial Market (2011), "It is also attractive to investors such as sovereign funds, institutions and private wealth investors from GCC and South East Asia regions seeking to diversify their reserves to invest in global Islamic investment portfolios and access the US markets by investing in US Sukuks issuances."

It has been observed from the first issue by Malaysia that there has been consistently high demand for Sukuks especially sovereign Sukuks. This has been proved by the oversubscription of the Sukuks issued by various countries around the globe. Islamic Finance News (2012) reports that in July, 2012 Qatar launched its first sovereign Sukuks for nine years. It was US \$ 4 billion dollars of amount with 'AA' rating by S\&P, and it attracted a huge demand of US \$ 24 billion dollars, demonstrating strong global demand for sovereign Islamic Sukuks. According to Malaysian ICM (2009), Indonesia issued US\$ 650 million of sovereign Sukuks and it received subscription of US\$ 4.7 biilion, seven times higher than the original issue.

There is a big opportunity available for investors both corporate and sovereign to diversify their risk of investment. Due to severe global crisis of 2008, they have big opportunity to invest in a secured opportunity in the form of sovereign Sukuks. Sukuks are alternative for investors both in the Muslim and Non-muslim 
communities. This has been true in the case of global financial crisis that Sukuks have been remained strong and sustainable but investment in the bonds was going down.

Global crisis has severely tarnished the picture of international financial sector and there were also some effects on the Sukuks market. But before the crisis there was a boom on corporate Sukuks, but after the crisis, especially Muslim economies have moved towards these asset backed securities due to their handsome benefits.

Governments of Muslim countries have a clear and viable option to introduce Islamic Finance all over the world with the help of Sovereign Sukuks Issues. This would be a big opportunity to give the world an alternative secured, sustainable and strong-footed financial system that may play a vigorous role in the economic development of both developed and developing countries. Islamic Finance News (2012) reports that Pakistan is the best example of Sukuks capital market and attracting capital investment in infrastructure development; and on the basis of this investment attraction, developing the overall Islamic financial industry.

According to Islamic Financial Services Board, the global Islamic finance assets are set to reach USD 1.6 th by 2012 from only around USD 150 bln in the mid-1990s. This was possible due to ample availability of petrodollars liquidity, encouraging demographics and efforts made by respective countries to promote Islamic Finance Market, (Kuwait Finance House Report, 2011).

Sovereign wealth funds have also taken into consideration the opportunity available to invest in Sukuks and they are contemplating and arranging meetings to invest in this huge area of finance. IMF and other big financial funds are also working on investing in sovereign Sukuks and they may diversify their risk by investing in Sukuks.

It may depend upon the macro-economic indicators of the country to issue Sukuks, but as has been the case in Pakistan, Sovereign Sukuks issued by Government of Pakistan, there has been over-subscription of these Sukuks. So, macro-economic indicators may not hamper the issue of sovereign Sukuks that may be issued by Government of Pakistan in the near future.

It is a viable option for developing countries that they can issue sovereign domestic Sukuks in their own currencies. Multiple currency option can also be exercised to accumulate huge funds for various public sector projects.

\section{Methodology}

This paper has been a literature review based paper. The data have been gathered from different articles. There was a dearth of articles available on Sukuks. But the focus of this research paper is on Sovereign Ijarah Sukuks for developing countries to raise infrastructure projects to attract foreign direct investment.

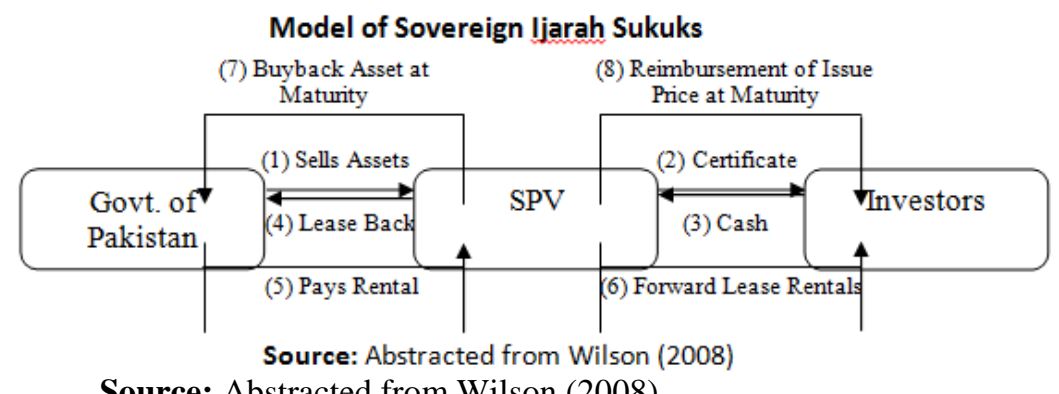

Source: Abstracted from Wilson (2008)

Islamic Finance News (2012) reports that in 2011 the most common structure was Sukuks Ijarah due its simplicity, flexibility and tradability. The lease basis of Ijarah Sukuks allows Governments to easily securitize their assets to get financing for various purposes as infrastructure development and/or financing the budget deficits. According to Mohamad Zaid Mohamad Zin (2011), "Ijarah Sukuks: It is divided into purchase agreement, lease agreement, servicing agreement and purchase undertaking. It is based on letting property rights to any other party based on agreed price. Al Ijarah Sukuks are issued on a sale and lease back arrangement (Ijarah) of real estate and have been a popular structure for sovereign issuers in particular. The issuer applies the Sukuks proceeds to purchase real estate from the originator and then leases it back to the originator. The originator undertakes to repurchase the real estate at maturity or upon early settlement at the original purchase price. The issuer is required by Shariah Law to undertake the major maintenance of the asset but will often appoint the obligor to carry out such activity on its behalf." In any given year, Ijarah structure represented between $25 \%$ and $70 \%$ of all Sukuks issued, Nurul Aini \& Rafisah Mat Radzi. (2011).

The basic considerations would be for developing countries to issue Sovereign Sukuk would be what assets should be used to get huge investment for infrastructure projects. The suggestion is that maximum public sector assets may be used for this high profile deal. United Arab Emirates has used its land as sovereign guarantee for issuing sovereign Sukuks. Islamic Finance News (2012), reports that Saudi Arabia's Civil 
Aviation Authority has launched US\$ 4 billion first Islamic Sukuks for the redevelopment of King Abdul Aziz Airport in Jeddah in March, 2012, on the guarantee of Ministry of Finance.

Credit rating of issuing of Sukuks is of much importance because if country receives high credit rating as 'AAA', it would have to pay lower rate of return on Sukuks as is the case with Malaysia and UAE for example. But in the case of low credit rating the country would have to pay high rate of return because of high risk involved in the transaction as is the case with Pakistan that receives or may receive low credit rating by international Islamic and Non-Islamic agencies and resultantly may have to pay high rate of return. Islamic Finance News (2012), reports that Malaysia receives high credit rating in issuing sovereign Sukuks. There is another aspect of rating that is not considered. Rating by Moody's, S\&P and Fitch do not comment on Islamic Shariah arm of the Sukuks. They only concentrate on payment of the return and principal amount of the Sukuks, Prof. Mahmood Faruqui.

\section{Analysis and Conclusion}

Developing countries can attract foreign direct investment by building infrastructure projects. These projects could be financed by issuing Sovereign Ijarah Sukuks. Many Muslim and non-Muslim countries have already issued or contemplating to issue sovereign Sukuks to finance their public sector infrastructure, energy projects and even financing the fiscal deficits by issuing sovereign Sukuks without even affecting the budget of the country. Islamic Finance News (2012) reports that this is because bond is a loan and it affects the balance sheet but Sukuks is a co-ownership in the respective tangible asset.

Islamic Finance News (2012) reports that "The capital market in Pakistan is now efficient, secure and popular avenue for handling excess liquidity, and Islamic institutions in the country have reportedly allocated almost $90 \%$ of the total investment towards sovereign Sukuks". According to Salman Ahmed Shaikh \& Shan Saeed, "The emergence of Sukuks as Islamic Bond in the financial markets heralds a new era which can provide much needed financial stability and mitigation of risk in these arduous times."

Especially the Muslim investors would watch the aspect of the Sukuks issues whether it is Shariah compliant or not. For example, the rate of return that is based on Libor plus or based on economic growth rate of the country. These rates of return are not based on Sharia'h but based on market circumstances or the economic conditions of the country. So, this aspect of Shariah needs attention to attract Muslim investors.

Islamic Finance News (2012) also tells us that "for 95\% of the times asset has no relevance with the profit or risk of the Sukuks and exists to give form over substance in compliance with Shariah guideleines. So this is a market driven approach (i.e. what investors want), not a religious one". According to Qais H Hamza (2006), within Shariah, regulations in one Muslim country may not be acceptable to other Muslim country.

According to Qais H Hamza (2006), in the case of conformity with Islam, raising finances is the top priority, but compliance with the principles of Shariah is top on that, the ethical screening that where the huge funds are exactly being invested and what assets are collateralized and how they are securitized is equally important.

There are four schools of thought of Sunni Fiqh, Malaysia follows Shafii School but rest of the Muslims in majority follows Hanfi Fiqh. So what could be done to bring harmony between at least these two fiqh to standardize the Islamic products so that Muslims and Non-Muslims conveniently invest in these products, Rodney Wilson.

[1]. Faruqui, P. M. (n.d.). Sukuks: Shariah-Western Law Matrix.

[2]. Hamza, Q. H. (2006). Islamic Sukuks Securities as Financing Instruments: An Examination of Bond Pricing in the Conventional and Islamic Setting and a Survey of Literature on Alternative Benchmarks to the Interest-Based System.

[3]. House, K. F. (2011). Sukuks "Back on Track".

[4]. ICM, M. (2009). Quarterly Bulletin of Malaysian Islamic Capital Market by the Securities Commission Malaysia.

[5]. Market, I. I. (2011). Sukuks Report: A Comprehensive Study of the Global Sukuks Market.

[6]. Mohamad Zaid Mohamad Zin, A. A. (2011). The Effectiveness of Sukuks in Islamic Finance Market.

[7]. Mohamad Zaid Mohamad Zin, N. H. (2011). The Implementation of Sukuks in Islamic Finance.

[8]. News, I. F. (2011). The World's Global Islamic Finance News Provider.

[9]. News, I. F. (2012). The World's Global Islamic Finance News Provider.

[10]. Radzi, N. A. (2011). Implication of Sukuks Structuring: The Comparison on the Structure of Asset Based and Asset Backed Ijarah Sukuks.

[11]. Saeed, S. A. (n.d.). Sukuks Bond: The Global Islamic Financial Instrument.

[12]. Tariq, A. A. (2004). Managing Financial Risks of Sukuks Structures.

[13]. Wedderburn-Day, R. (2010). Sovereugn Sukuks: Adaptation and Innovation.

[14]. Wilson, R. (n.d.). (I. C. Sukuks, Editor) Retrieved from http://www.qfinance.com. 